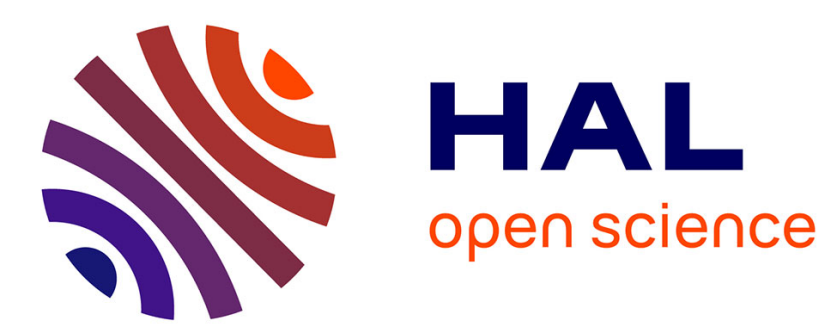

\title{
An apparatus for absorption measurements in the far infrared by Fourier transform
}

\author{
P. Meyer, D. Petitgrand
}

\section{To cite this version:}

P. Meyer, D. Petitgrand. An apparatus for absorption measurements in the far infrared by Fourier transform. Revue de Physique Appliquée, 1976, 11 (5), pp.661-664. 10.1051/rphysap:01976001105066100 . jpa-00244101

\section{HAL Id: jpa-00244101 https://hal.science/jpa-00244101}

Submitted on 1 Jan 1976

HAL is a multi-disciplinary open access archive for the deposit and dissemination of scientific research documents, whether they are published or not. The documents may come from teaching and research institutions in France or abroad, or from public or private research centers.
L'archive ouverte pluridisciplinaire HAL, est destinée au dépôt et à la diffusion de documents scientifiques de niveau recherche, publiés ou non, émanant des établissements d'enseignement et de recherche français ou étrangers, des laboratoires publics ou privés. 


\title{
AN APPARATUS FOR ABSORPTION MEASUREMENTS IN THE FAR INFRARED BY FOURIER TRANSFORM
}

\author{
P. MEYER and D. PETITGRAND $\left({ }^{*}\right)$
}

Laboratoire de Physique des Solides (**)

Université Paris Sud, 91405 Orsay, France

(Reçu le 8 mars 1976, accepté le 21 mai 1976)

\begin{abstract}
Résumé. - L'article donne la description d'un système complet destiné à l'étude dans l'infrarouge lointain de matériaux magnétiques à des températures aussi basses que $1,3 \mathrm{~K}$ et à des champs magnétiques allant jusqu'à 7,5 T. Les bonnes performances de l'ensemble sont illustrées par des résultats sur $\mathrm{FeCl}_{2}$ et les ions de $\mathrm{Fe}^{2+}$ dans $\mathrm{MgO}$.
\end{abstract}

Abstract. - The description of a complete system for far infrared studies of magnetic materials at temperatures as low as $1.3 \mathrm{~K}$ and magnetic fields up to $7.5 \mathrm{~T}$ is given. The good overall performance is demonstrated by the results on $\mathrm{FeCl}_{2}$ and $\mathrm{Fe}^{2+}$ ions in $\mathrm{MgO}$.

1. Introduction. - For absorption experiments in solids in the far infrared between 10 and $250 \mathrm{~cm}^{-1}$ Fourier transform techniques offer certain advantages over a classical grating spectrometer :

- for a comparable measuring time a much better signal to noise ratio,

- direct wavelength calibration,

- precise knowledge of the instrumental profile.

In this wavelength range interferometers of the Michelson- or Twyman-Green type seem to be the most convenient instruments. One drawback with commercial interferometers is that, while working satisfactorily at low optical densities and samples at room temperature, they are normally not equipped for low temperature work and the standard detector they are supplied with, the Golay-cell, is not sensitive enough for experiments on dilute ions in a more or less absorbing matrix, e. g. $\mathrm{Fe}^{2+}$ in $\mathrm{MgO}$.

So the necessary modifications and additions to such an instrument must take into account the following points :

- Sample temperature between 1.3 and $50 \mathrm{~K}$.

- Low temperature bolometer such as Ge : Ga.

- Possibility to apply a magnetic field.

With these conditions in mind it becomes clear that the cryogenics part of the installation must be given particular thought.

(*) Also CEN-Saclay DPh-EP, 91190 Gif-sur-Yvette, France.

$(* *)$ Laboratoire associé au C. N. R. S..

REVUE DE PHYSIQUE APPLIQUÉE. - T. 11, No 5, SEPTEMBRE 1976
In this paper we wish to present the final stage of construction of an instrument conceived along such lines that has been operative now for several months.

As an example for the results obtained so far, we give the spectra of $\mathrm{Fe}^{2+}$ ions in $\mathrm{MgO}$ and the antiferromagnetic resonance (AFMR) mode of $\mathrm{FeCl}_{2}$, a typical layered structure.

2. Interferometer. - We started out with a BECKMAN/RIIC FS 720 module, which had already proved to be a very sturdy an mechanically sound instrument. The continuous mirror drive with a Moiré-frange system to monitor the path-difference was too wasteful of measuring time and not reliable enough. It was replaced by a stepping motor (SLO SYN SS25) driving directly the micrometer screw originally mounted in the instrument. A simple control unit was built generating repeatedly the appropriate measuring cycle :

- Rapid advance of the mobile mirror by a determined number of steps.

- Integrating period of several time-constants of the signal amplifier.

- Digitization and recording on punched tape.

In order to judge the quality of the lead screw and general positioning precision of the stepping motor we compared a water-vapour spectrum in the range between 40 and $150 \mathrm{~cm}^{-1}$ with one published by Rao et al. [1] and found an agreement of the absorption frequencies better than $0.05 \mathrm{~cm}^{-1}$, that is to say, better than the resolution of the spectra.

The source, a Philips HPK 125 high-pressure mer- 
cury arc, was originally choke-fed on AC. Its stability and longevity could be greatly improved by the use of a regulated current supply of $300 \mathrm{~V}, 2 \mathrm{~A}$ in series with a $100 \Omega$ resistor. The long-term stability of the operating current ( $1 \mathrm{~A}$ ) is of the order of $2 \times 10^{-4} \mathrm{~A}$.

The light of the source passes a variable-frequency chopper permitting the use of a Golay-cell at typically $10 \mathrm{~Hz}$ as well as operation of a bolometer detector at its optimum frequency. This is achieved by feeding the coils of the modulator motor with two currents of variable frequency but a fixed phase difference of $90^{\circ}$.

3. Cryostat. - A cryostat has been built to meet the various requirements of far infrared spectroscopy of magnetic compounds such as $\mathrm{FeCl}_{2}$ or isolated magnetic ions, pairs or triads in a non-magnetic matrix. It permits controlled sample temperature between 1 and $50 \mathrm{~K}$ and application of a magnetic field of up to

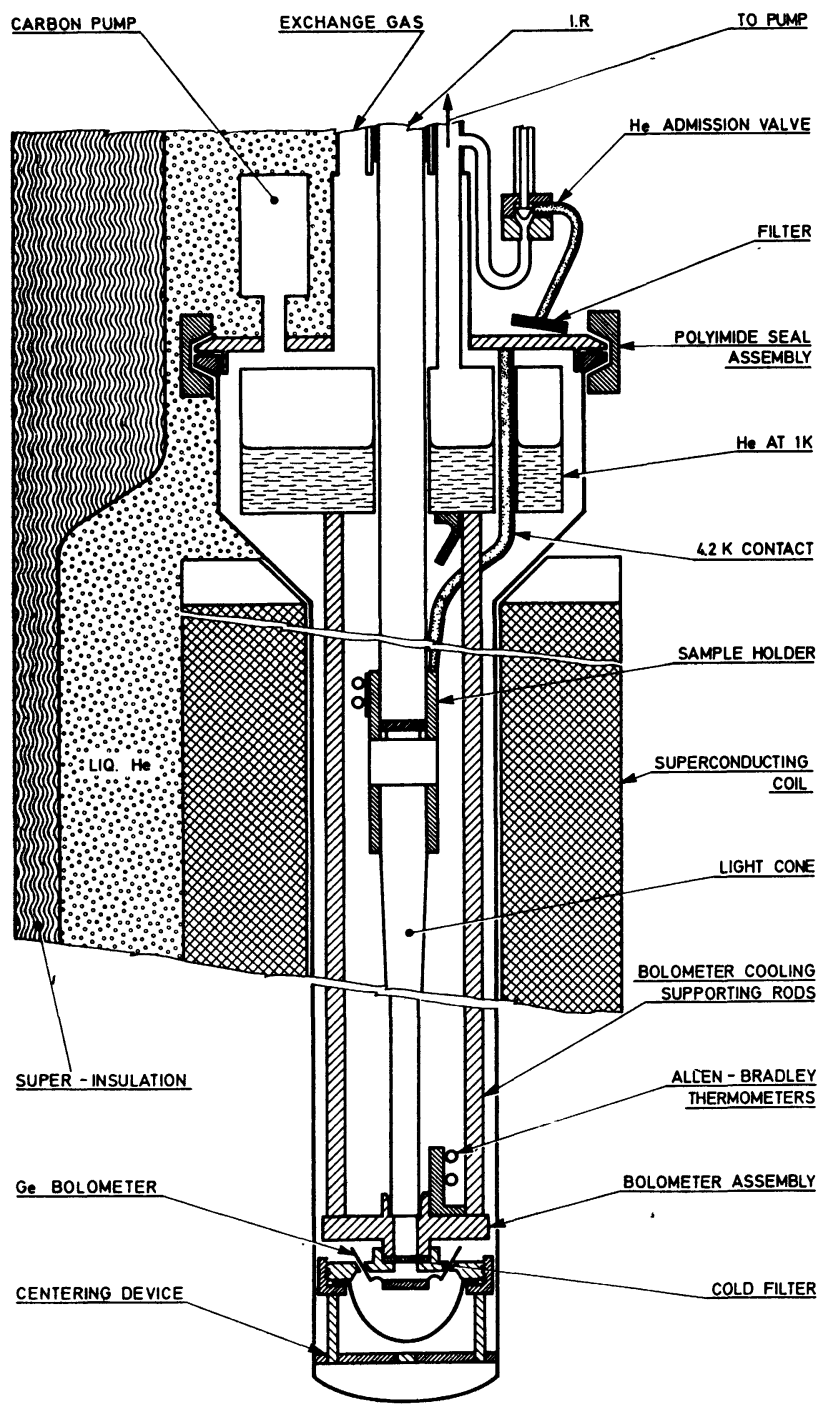

FIG. 1. - Schematic view of the cryostat and bolometer housing. The sample holder is shown coupled to the $4.2 \mathrm{~K}$ point, a copper rod fixed to the upper flange and passing through an insulated opening in the pumped helium can. It may alternatively be coupled to the latter by soldering the copper braid to a lug on its underside.
7.5 $\mathrm{T}$ in the vertical direction. It is further equipped with a $\mathrm{Ge}: \mathrm{Ga}$ Bolometer working normally at $1.3 \mathrm{~K}$ controlled to better than $2.5 \mathrm{mK}$.

Sample and bolometer (Fig. 1) are both coupled to a pumped helium bath inside a long cylindrical enclosure, which is placed in liquid helium contained in a complete superinsulated Dewar. This cylinder is filled at ambient temperature with about $2 \times 10^{3} \mathrm{Nm}^{-2}$ (15 torr) of helium. While cooling down the exchange gas pressure is maintained by heating the active-carbon cryo-pump. Upon arriving at $4.2 \mathrm{~K}$ the exchange gas is removed by turning off the heater current.

Liquid helium can be admitted into the inner thermostat via a needle-valve connecting it with the surrounding bath. This thermostat is pumped by a $20 \mathrm{~m}^{3} / \mathrm{h}$ two-stage rotary pump and attains in the limit a temperature of about $1.03 \mathrm{~K}$. The thermal loss of the Dewar is only $70 \mathrm{~mW}$, thus giving an autonomy of 8 hours.

The superconducting solenoid may be fastened on the exterior of the sample enclosure with the bolometer well out of the magnetic field. With the magnet in operation the time between two top-ups necessary to keep the sorption pump covered by helium drops to about $3 \mathrm{~h}$ in the worst case of fields higher than $4 \mathrm{~T}$ and external feeding of the coil.

Light from the interferometer is picked up by a brass light-pipe at the focusing point in the former sample chamber. After passing a sealed TPX window, fixed in a Leybold-type quick-release coupling, it is guided down to the sample holder (Fig. 2) and the bolometer. The light-pipes in the cryostat are of thin-walled stainless steel to suppress thermal coupling between the outer helium, the sample holder whose temperature is variable between 1.1 and $50 \mathrm{~K}$ and the bolometer whose temperature is fixed at $1.3 \mathrm{~K}$.

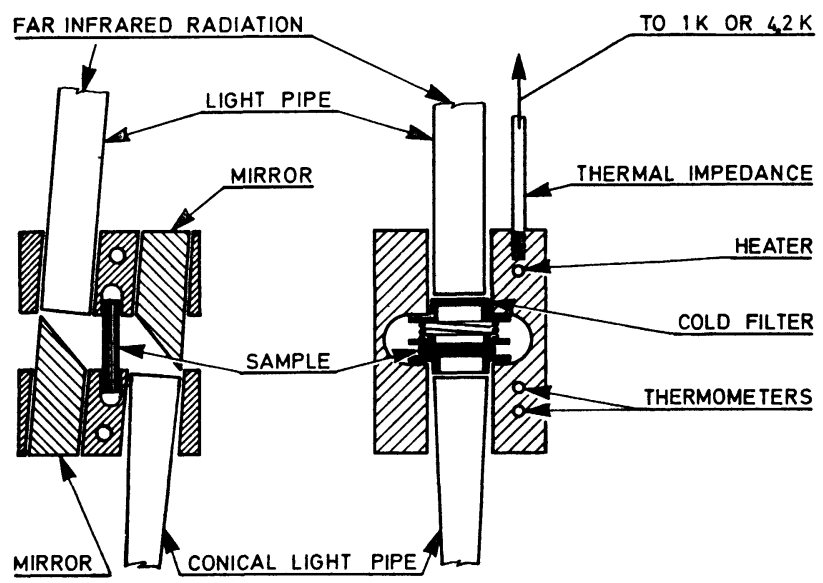

FIG. 2. - Detail of the sample holders. The magnetic field is vertically oriented.

We use two types of sample holders (Fig. 2) : One with a straight-through passage of the radiation for isotropic samples and layered structures with their c-axis parallel to the field direction. The other allows 
the c-axis of the layered samples to be oriented perpendicularly to the field direction while keeping the wave vector of the radiation parallel to the c-axis. This is done by two mirrors at $45^{\circ}$. The resulting kink in the light path is readily taken care of by inclining the lightpipes. So the positions of sample holder and bolometer housing do not change.

4. Bolometer. - As infrared detector we opted for a $\mathrm{Ge}$ : $\mathrm{Ga}$ bolometer for its outstanding performances in detectivity and N. E. P. The theory of this type of bolometer has already been extensively treated by several authors [2], [3] so we limit ourselves to an outline of the preparation and the performance of the bolometer we have mounted.

A slice of Ga-doped Ge was cut from a boule of appr. $0.1 \Omega \mathrm{cm}$ resistivity. After cutting and lapping the sample was etched in mild alcohol etchant $\left(10 \mathrm{ml} \mathrm{HNO}_{3} 60 \%+10 \mathrm{ml} \mathrm{HF} 38 \%+1 \mathrm{ml}\right.$ Etha$\mathrm{nol}+18 \mathrm{ml}$ dist. water). The final dimensions of the bolometer are $6 \times 10 \times 0.1 \mathrm{~mm}^{3}$.

Ohmic contacts were obtained by copperplating two corners of the chip in a classical acid copper-sulfate bath and soldering with indium the copper leads of $0.1 \mathrm{~mm}$ diameter serving as electrical connection, thermal impedance and mechanical support for the bolometer. The leads, of a final length of about $10 \mathrm{~mm}$, have a thermal impedance of $55 \mu \mathrm{Wdeg}^{-1}$. The bolometer housing (Fig. 1), is coupled to the pumped $\mathrm{He}$ bath by its suspending two copper tubes and is equipped with a carbon thermometer and a heater resistance.

The value of the ambient resistivity of $\sim 0.1 \Omega \mathrm{cm}$ seems to indicate that the germanium used might be too highly doped. However, preliminary measurements of the $R / T$ relationship yielded a value of the activation temperature

$$
E / k=\mathrm{d}(\log R) / \mathrm{d}(1 / T)
$$

of $E / k=5.6 \mathrm{~K}$ at the temperature of $1.3 \mathrm{~K}$, close to the values reported by other authors [2], [3].

The responsitivity at the operating point of $1.3 \mathrm{~K}$ was determined by the static method as used by previous authors [2], [4] which is based on on the $V / I$ relationship :

$$
S=\frac{(Z-R)}{2 V} \cdot \frac{R 1}{R 1+Z}=40 \mathrm{kVW}^{-1}
$$

where

$V$ is the voltage across the bolometer,

$R=V / I$ its resistance $(427 \mathrm{k} \Omega)$,

$Z=\mathrm{d} V / \mathrm{d} I$ its dynamic resistance $(362 \mathrm{k} \Omega)$ and

$R 1$ the load resistance ( $10 \mathrm{M} \Omega$ metal-film at $4.2 \mathrm{~K}$ ).

The thermal conductance is given by

$$
G=\mathrm{d} P / \mathrm{d} T=(\mathrm{d} P / \mathrm{d} R) \cdot(\mathrm{d} R / \mathrm{d} T)
$$

and can be obtained through the $P(I)$ plot and the thermal measurement of $R(T)$.
Since we are principally interested in the bolometer as an IR-detector that is part of a complete experimental setup for measuring absorption, we prefer to evaluate its noise performance in conjunction with the associated equipment such as biasing source and lockin amplifier.

The noise voltage thus understood, estimated by the noise at the output of a PAR 128 lock-in amplifier was better than $0.2 \mu \mathrm{V}$ in a $1 \mathrm{~Hz}$ bandwidth. This gives with the previous value for $S$ a

$$
\mathrm{NEP}=5 \times 10^{-12} \mathrm{WHz}^{-1 / 2} .
$$

The detector time-constant $\tau$ was obtained by observing the variation of the phase angle with rising modulation frequency. $45^{\circ}$ is reached at about $40 \mathrm{~Hz}$ which yields

$$
\tau=1 /\left\{2 \pi \cdot f\left(45^{\circ}\right)\right\}=4 \times 10^{-3} \mathrm{~s} .
$$

We therefore adopted an operating frequency of $f=35 \mathrm{~Hz}$.

The following table lists again the pertinent characteristics of the detector :

$\operatorname{Dim}=6 \times 10 \times 0.1 \mathrm{~mm}^{3}, \quad T=1.3 \mathrm{~K}$, $I=1.9 \mu \mathrm{A}, \quad R=427 \mathrm{k} \Omega$, $R 1=10 \mathrm{M} \Omega, \quad \mathrm{d}(\ln R) / \mathrm{d}(1 / T)=5.6 \mathrm{~K}$, $G=55 \times 10^{-6} \mathrm{WK}^{-1}, \quad \tau=4 \times 10^{-3} \mathrm{~s}$, $f=35 \mathrm{~Hz}, \quad S=40 \mathrm{~kW}^{-1}$. $N E P=5 \times 10^{-12} \mathrm{WHz}^{-1 / 2}$,

5. Conclusion. - The best way to show satisfactory functioning of the apparatus as a whole is to give samples of spectra actually measured with it.

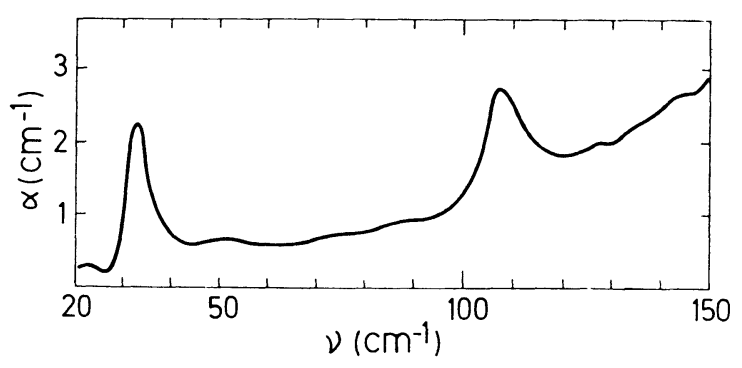

Fig. 3. - Far infrared absorption spectrum of $\mathrm{Fe}^{2+}$ ions in $\mathrm{MgO}$ $(0.43 \% \mathrm{Fe})$ at $4.2 \mathrm{~K}$. Resolution is about $4 \mathrm{~cm}^{-1}$.

Figure 3 shows the absorption spectrum of $\mathrm{Fe}^{2+}$ ions in $\mathrm{MgO}(0.43 \% \mathrm{Fe})$, an example of a dilute system. The sample temperature was $4.2 \mathrm{~K}$. The resolution is $\sim 4 \mathrm{~cm}^{-1}$, whereas the frequency range is relatively large. The peak at $107 \mathrm{~cm}^{-1}$ is due to the (here unresolved) $\Gamma_{5 \mathrm{~g}} \rightarrow \Gamma_{3 \mathrm{~g}}$ and $\Gamma_{5 \mathrm{~g}} \rightarrow \Gamma_{4 \mathrm{~g}}$ transitions of the splitted ground-state of the Fe-ion [5], [6]. The absorption at $33 \mathrm{~cm}^{-1}$ may be due to Fe-pair interaction. The interferogram was taken with a $50 \mathrm{G}$ $(0.012 \mathrm{~mm})$ Mylar beamsplitter and sampled on 250 points up to the maximal path-difference of $\pm 0.25 \mathrm{~cm}$. The recording took about one hour. Under 
these conditions the smallest detectable value of the absorption coefficient for a sample of $1 \mathrm{~cm}$ thickness would be of the order of $0.1 \mathrm{~cm}^{-1}$.

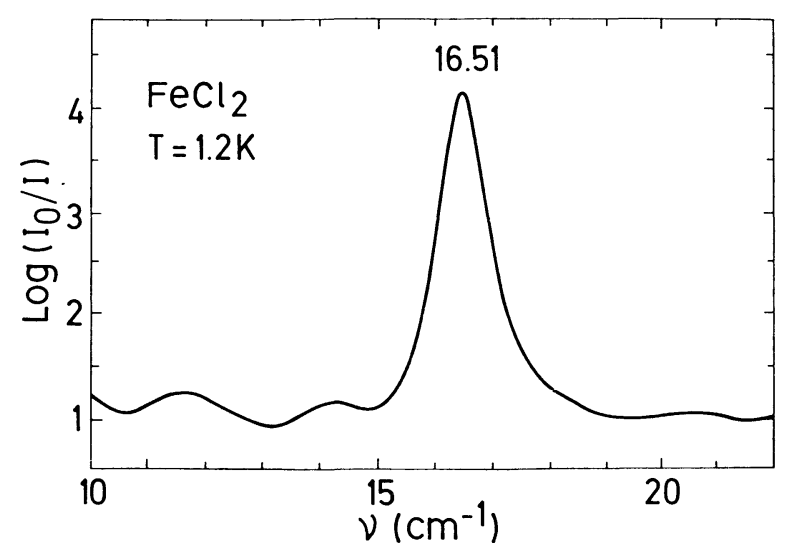

FIG. 4. - Far infrared absorption of the AFMR-mode in $\mathrm{FeCl}_{2}$

Figure 4 shows the AFMR-mode absorption in $\mathrm{FeCl}_{2}$ which is situated on the lower side of our operating range $\left(5-250 \mathrm{~cm}^{-1}\right)$. The interferogram of 1550 sampling points and a maximal optical pathdifference of $\pm 6 \mathrm{~cm}$ was taken with a $400 \mathrm{G}(0.1 \mathrm{~mm})$ Mylar beamsplitter. The recording took about two hours using a $5 \mathrm{~s}$ integrating period. Since the thickness of the sample was $0.1 \mathrm{~cm}$, the peak presents an absorption coefficient of $40 \mathrm{~cm}^{-1}$. The position of the peak, $16.51 \mathrm{~cm}^{-1}$, was reproducible to $\pm 0.03 \mathrm{~cm}^{-1}$ on different runs. The resolution here is about $0.25 \mathrm{~cm}^{-1}$ and we deduce that the transition has a natural width of $1.2 \mathrm{~cm}^{-1}$.

Acknowledgments. - At this point we wish to thank $O$. Testard who designed the cryostat and J. Le Ny for assembling and testing the cryogenic equipment. We are further very grateful to A. Boix who constructed the mirror-control logic and the temperature regulators.

The detector material has been contributed by B. Pajot with whom we had also many fruitful discussions on the subject.

\section{References}

[1] RaO, K. N., De Vore, R. V. and Plyler, E. K., J. Res. Nat. Bur. Stand. 67A (1963) 351.

[2] Zwerdling, S., Smith, R. A. and Theriault, J. P., Infr. Phys. 8 (1968) 271.

[3] Hadni, A., Strimer, P. and Thomas, R., Nouv. Revue Opt. Appl. 2 (1971) 379.
[4] Jones, R. C., J. Opt. Soc. Am. 43 (1953) 1.

[5] Meyer, P., Regis, M. and Farge, Y., Phys. Lett. 48A (1974) 41.

[6] Huortsberg, A., Nygren, B. and Vallin, J. T., Sol. Stat. Commun. 16 (1975) 105. 